\title{
Kredibiliti Dan Kontroversi Tokoh Sahabat Ibn Mas'ud r.a
}

Ahmad Zulfiqar Shah bin Abdul Hadi, Mohd Abdul Nasir bin Abd Latif ${ }^{a}$

a Jabatan Pengajian Islam, Fakulti Sains Kemanusiaan, Uni. Pendidikan Sultan Idris

*Corresponding author: ahmadzulfiqarshah@yahoo.com

\begin{abstract}
Article history
Received: 2014-05-26

Received in revised form: 2014-09-26

Accepted: 2014-10-26

Abstract

Ibn Mas'ud was a leading figure among the Companions of the Prophet Muhammad SAW. He was recognized as a credible scholar in the sciences of Al-Qur'an, Hadith (traditions of the Prophet SAW) and attained high reputations among the Companions and the Tabi'in. Nevertheless, there were some allegations hurled against him that includes his omission of al-Mu'awwidhatayn and al-Fatihah as parts of al-Qur'an; his rejection of the al-Qur'an compilation committee; his different arrangement of chapters in al-Qur'an and his refusal to hand over his copies of al-Qur'an to be burnt. Analysis has been made based on various documentary resources from the books of tafsir, Qiraat, Hadith and history. From the analysis, those allegations were false, with malicious intent and those who made it clearly wanted to take advantage on his reputation. It can be concluded that the originality of al-Qur'an was undermined by certain quarters while the Shiites' claims were made to justify their religious doctrines using his name.
\end{abstract}

Keywords: Biography of Ibn Mas‘ud, Mashaf Ibn Mas‘ud, Controversy on Ibn Mas'ud, Authneticity of Mashaf 'Uthmani. 


\subsection{Pendahuluan}

Perbincangan tentang Ibn Mas ūd r.a telah banyak dibincangkan dalam pelbagai buku, artikel dan tulisan ilmiah. Al-Sakhāwì (2008) menyatakan "Manāqib beliau (Ibn Mas'ūd r.a) amatlah banyak, (sekiranya ditulis) ia mengandungi banyak halaman muka surat". Begitu juga kenyataan yang dinyatakan oleh Ibn al-Qayșarāni (1994) menyatakan "Sekiranya dikumpulkan) mungkin biografi Ibn Mas 'üd r.a boleh dikumpulkan sehingga setengah jilid". Antara karya yang berkaitan ialah sebuah tesis peringkat kedoktoran yang dihasilkan oleh Dr. Manșūr Ibn 'Awn Al-Abdili yang bertajuk "Marwiyāt 'Abd Allāh Ibn Mas' ùd r.a fì al-Kutub al-Sittah, Muwattā' Imam Mālik, Musnad Imām Ahmad", dan begitu juga 'Abd al-Sattār al-Shaykh dalam kitabnya "Abd Allāh Ibn Mas' üd r.a Dimn Silsilah 'Alām Șahābah". Selain itu terdapat satu buku karangan Mạ̣mūd Shalabi (1995) bertajuk "Hayāh 'Abd Allāh Ibn Mas ' $\bar{d}$ " juga merupakan kumpulan daripada riwayat dan penceritaan dalam bentuk santai yang dikemukakan oleh pengarang tentang biografi Ibn Mas'ūd r.a.

Setelah kewafatan Rasulullah SAW, Islam tersebar secara meluas ke kebanyakan pelosok Arab. Pada zaman pemerintahan Khalifah 'Umar al-Khațāab, 'Abd Allāh Ibn Mas ūd r.a. telah diutuskan ke Kufah, Iraq untuk menjadi guru dan pengasas Islam di sana (Muhammad Rawwās Qal'ahji 1984). Keadaan ini menjadikan penduduk Kufah membaca al-Qur'an dengan Qiraat Ibn Mas'ūd r.a. (Ahmmad 'İsa al-Ma șarawi 2006). Namun, semasa peristiwa pengumpulan dan penulisan semula al-Qur'an pada zaman 'Uthmān r.a, terdapat sebahagian daripada Qiraat Ibn Mas' ūd r.a dipinggirkan dan dikira sebagai qiraat yang janggal (shädhdhah). Selain itu, terdapat dakwaan yang kontroversi menyatakan keengganan Ibn Mas ūd r.a mengiktiraf Mașhaf Uthmāni, susunan surah yang berlainan dengan Mașhaf 'Uthmānì, tiga surah, iaitu al-Fätihah, al-Falaq dan al-Nās tidak dikira sebagai ayat al-Qur'an, susunan surah yang berbeza, perbezaan kalimah al-Qur'an, penambahan dan pengurangan kalimah dan frasa serta mendahului dan mengakhirkan perkataan dan frasa dalam ayat al-Qur'an.

\subsection{Nasab dan Keturunan}

Ibn Mas ūd r.a merupakan antara sahabat Rasulullah SAW yang amat popular dalam dunia Islam. Nama penuh beliau ialah 'Abd Allāh Ibn Mas'ūd r.a Ibn Ghāfil Ibn Habīb Ibn Syamkh Ibn Fār Ibn Makhzūm Ibn Șahỉlah Ibn Kahỉl Ibn al-Ḥārith Ibn Tamīm Ibn Sa ad Ibn Hudhayl Ibn Mudrikah Ibn Ilyāṣ Ibn Mudīi al-Huzlì, Abū 'Abd al-Raḥmān. (Ibn al-Athīr 1987). Muhammad Ibn Ishāq (2004) dan Ibn Ḥibbān $(1417 \mathrm{H})$ telah berselisih pendapat berhubung nama datuk beliau, iaitu Ghāfil dan Ḥabīb dengan menggantikan nama kedua datuk "Abd Allāh Ibn Mas ūd r.a dengan al-Ḥārith.

Para pengkaji yang menulis tentang biodata 'Abd Allāh Ibn Mas ūd r.a menyatakan beliau adalah keturunan Bani Zuhrah. Antara yang menyatakan demikian ialah Ibn Hajar al-'Asqalānī (2008): "Sesungguhnya dia mempunyai talian keluarga dengan 'Abd al-Hāris Ibn Zuhrah". Ibn "Abd al-Barr (1412 H) juga menyatakan "Dia adalah (berketurunan) 'Abd Allah Ibn Haris Ibn Zuhrah". Ibn al-Athir (1987) menyatakan "Bapanya (Ibn Mas' ūd), iaitu Mas üd merupakan sekutu Abd al-Hāris Ibn Zuhrah pada zaman jahiliyyah manakala ibunya Umm 'Abd Allāh binti 'Abd Wudd Ibn Suwā' juga daripada (kaum) Hudhayl".

\subsection{Gambaran Fizikal}

Secara fizikalnya, Ibn Mas ūd r.a merupakan seorang yang berbadan kecil dan kurus sehingga diriwayatkan ketinggiannya badannya adalah setara dengan orang lain yang duduk. Rambut beliau juga melepasi paras telinga dan tidak mengubah uban rambutnya. (Ibn "Abd al-Barr $1412 \mathrm{H}$ ). Imam alTTabrāni (1983) meriwayatkan bahawa beliau mempunyai betis yang agak kecil manakala al-Dhahabi menukilkan dengan menyatakan Sa ìd Ibn Musayyib semasa tahun kewafatan Ibn Mas ūd r.a dia mempunyai perut yang agak besar. Qays Ibn Abī Hāazim meriwayatkan bahawa Ibn Mas ūd r.a 
merupakan seorang yang amat rendah badannya namun mempunyai otak yang cerdas dan pintar. (alDhahabi 1996).

\subsection{Kewafatannya}

Majoriti ahli sirah (sejarah hidup Nabi Muhammad SAW) berpendapat bahawa Ibn Mas ùd r.a meninggal pada tahun 32 Hijrah di Madinah al-Munawwarah pada usia lebih 60 tahun. Menurut Ibn al-Athï (1987), kewafatan Ibn Mas'ūd adalah sebelum berlakunya pembunuhan Khalifah 'Uthmān r.a. Jasad beliau dikebumikan di sebelah kubur 'Uthmān Ibn Maz' ūn yang terletak di perkuburan Baqi' setelah selesai Zubayr ibn al-“Awwām mengimamkan solat jenazahnya berdasarkan wasiat beliau.

\subsection{Reputasi dan Kemasyhuran Ibn Mas'ūd r.a}

\subsection{Pengislaman}

Ibn Mas ūd r.a merupakan antara yang terawal memeluk Islam. Diriwayatkan beliau telah masuk Islam bersama-sama dengan Sa ìd Ibn Zayd dan isterinya Fāṭimah binti al-Khaț̣āb yang merupakan adik kepada 'Umar bin al-Khațtāb. (Ibn Athïr 1987). Menurut riwayat daripada anak Ibn Mas'ūd yang bernama 'Abd al-Raḥmān bahawa ayahnya Ibn Mas'ūd r.a pernah berkata : "Aku mendapati yang aku merupakan orang yang keenam sebagai muslim di bumi ini, orang yang pertama membaca dengan kuat bacaan al-Qur'an di Makkah, berhijrah sebanyak dua kali, solat bersama Rasulullah SAW semasa pertukaran qiblat, bersama-sama dengan Rasulullah SAW dalam peperangan Badar, Uhud, Khandaq dan Bayat al-Ridhwān ..”. (al-Hākim, 1990). Ibn Hajar al-'Asqalāni (2008) berkata: "Adalah beliau (Ibn Mas 'ūd) memeluk Islam pada awal-awal Islam. Ketika Sa ìd Ibn Zayd dan isterinya Fātimah binti al-Khaț̣̂ab telah memeluk Islam, jauh berbanding "Umar memeluk Islam".

\subsection{Berperwatakan dan Berakhlak Persis Rasulullah SAW}

Dalam menceritakan tentang perwatakan yang boleh digambarkan tentang peribadi Ibn Mas'ud r.a, Imam Ahmad telah meriwayatkan bahawa keperibadian Ibn Mas'ud r.a adalah amat dekat dengan perwatakan Rasulullah SAW. Kenyataan ini berdasarkan periwayatan daripada 'Abd al-Raḥmān Ibn Zayd "Kami telah berkata kepada Hudhayfah: Khabarkan kepada kami seseorang yang amat hampir perwatakan dan kemuliaannya dengan Rasulullah SAW sehingga kami boleh mengambil (ilmu dan akhlak) daripadanya. Hudhayfah r.a berkata : Aku tidak mengetahui tentang (orang lain) yang amat dekat perwatakan dan kemuliaan dengan Rasulullah SAW sehinggakan dinding rumah Rasulullah SAW melekat dengan (dinding rumah) Ibn Umm 'Abd”. (Ahmad bin Hanbal, 1993 : No. hadis : 22260).

\subsection{Keberanian dan Keperwiraan}

Ibn Mas' ūd r.a juga dikenali sebagai seorang yang berani dalam menyampaikan Islam. Ini terbukti berdasarkan periwayatan tentang keberaniannya membaca al-Qur'an dengan suara yang kuat di Masjid al-Haram pada zaman awal Islam. Disebabkan itu beliau telah dibelasah oleh kaum Musyrikin Mekah namun itu tidak menjadi halangan untuk beliau lantaran keberaniannya (Ibn al-Athï 1987).

Selain itu Ibn Mas'ūd r.a adalah orang yang telah memancung kepala Abu Jahal dalam Perang Badar. Menurut riawayat Imam Muslim $(1365 \mathrm{H})$ bahawa dalam peperangan Badar, Abu Jahal telah diasak hebat oleh Mu ādh Ibn 'Amr Ibn Jamūḥ dan Mu'awwidh Ibn Arfa', atau Mu'ādh Ibn Hāāith. Sewaktu Ibn Mas ūd menemui Abū Jahal yang berada dalam keadaan hampir cedera parah, beliau telah bertindak memegang janggut Abu Jahal lalu dengan suara yang terputus-putus dan bernada sombong Abu Jahal berkata: "Aku tidak merasa hina kerana aku dibunuh oleh kaumku sendiri". Tanpa ada melengahkan waktu, pedang Ibn Mas'ūd terus memenggal kepala Abū Jahal. 


\subsection{Pengiktirafan Terhadap Ibn Mas' ${ }^{\mathbf{u}} \mathbf{d}$}

Kedudukan Ibn Mas'ūd r.a yang tinggi lagi dihormati dalam kalangan sahabat jelas terbukti berdasarkan banyak periwayatan menceritakan tentang kelebihannya. Pengiktirafan ini bukan hanya dalam kalangan sahabat dan para tokoh lain bahkan Ibn Mas'ūd r.a juga turut mendapat pengiktirafan dalam al-Qur'an, Rasulullah SAW, para sahabat dan murid beliau yang tergolong dalam kategori tabiin.

\section{i. $\quad$ Pengiktirafan al-Qur'an Terhadap Ibn Mas'ūd}

Al-Qur'an telah menyatakan dengan jelas pengiktirafan Allah S.W.T kepada para sahabat Rasulullah SAW dan kelebihan mereka termasuklah Ibn Mas'ūd. Antara ayat yang menyatakan keutamaan sahabat ialah firman Allah SWT dalam Surah al-Taubah, 9: 100: "Dan orang-orang yang terdahulu - yang mula-mula (berhijrah dan memberi bantuan) daripada orang-orang Muhajirin dan Ansar, dan orang-orang yang menurut (jejak langkah) mereka dengan kebaikan (iman dan taat), Allah reda akan mereka dan mereka pula reda akan Dia, serta ia menyediakan untuk mereka syurga-syurga yang mengalir di bawahnya beberapa sungai, mereka kekal di dalamnya selama-lamanya; itulah kemenangan yang besar".

Selain itu, Ibn Mas ūd r.a pernah mentafsirkan ayat 172 surah Āli Imrān (yang maksudnya: Orangorang yang menjunjung perintah Allah dan Rasul Nya (supaya keluar menentang musuh yang menceroboh), sesudah mereka mendapat luka (tercedera di medan perang Uhud) dengan katanya: "Sesungguhnya dalam kalangan kami ada 18 orang" (Ibn Abi Ḥātim, 1419H).

\section{ii. $\quad$ Pengiktirafan Rasulullah SAW Terhadap Ibn Mas' ${ }^{\mathbf{u}} \mathrm{d}$}

Pengiktirafan terhadap kepakaran Ibn Mas'ūd dalam bidang al-Qur'an boleh dilihat menerusi empat aspek. Aspek pertama ialah permintaan Rasulullah SAW agar diperdengarkan bacaan kepada Nabi SAW. Dalam hal ini al-Bukhāri (1998) meriwayatkan bahawa Nabi SAW telah meminta kepada Ibn Mas' ūd agar dibacakan al-Qur'an kepada baginda sedangkan al-Qur'an itu diturunkan kepada baginda. Ini menunjukkan bahawa Rasulullah SAW suka terhadap bacaan yang diperdengarkan oleh Ibn Mas' ‘̄d r.a.

Aspek kedua pula ialah pengiktirafan sebagai rujukan utama al-Qur'an. Imam al-Bukhāri (1998) meriwayatkan bahawa Rasulullah SAW bersabda; “Ambillah (pelajarilah) al-Qur'an daripada empat (orang), iaitu daripada 'Abd Allāh Ibn Mas' ùd, Sālim (Hamba Abu Hudhayfah) Mu'ādh Ibn Jabal dan Ubayy Ibn Ka ab". Aspek ketiga pula ialah pengiktirafan sebagai sahabat yang mempunyai bacaan yang tepat dan sesuai dengan bacaan ketika ayat tersebut diturunkan. Sehubungan dengan itu, al-Hāaim (1990) meriwayatkan bahawa Rasulullah SAW bersabda yang maksudnya; "Sesiapa yang ingin membaca al-Qur'an tepat sebagaimana diturunkan maka bacalah sepertimana bacaan Ibn Umm 'Abd".

Manakala aspek keempat pula ialah pengiktirafan terhadap pengetahuan yang luas tentang setiap peristiwa dalam penurunan al-Qur'an. Dalam sebuah hadis riwayat Muslim (1365H) bahawa Ibn Mas'ūd berkata "Dan tidak ada selain daripadanya yang mengetahui tentang kitab Allah satu surah kecuali aku mengetahui di mana ia diturunkan. Juga tidak ada ayat kecuali aku mengetahui dalam keadaan mana ia diturunkan. Dan sekiranya aku mengetahui ada seorang yang lebih mengetahui berkenaan dengan kitab Allah (lebih) daripada aku, nescaya akan aku capai untaku dan pergi menemuinya".

\section{iii. $\quad$ Pengiktirafan Para Sahabat Rasulullah SAW Terhadap Ibn Mas'}

Para sahabat menyifatkan Ibn Mas'ūd sebagai seorang yang tinggi ilmu agama. Dalam hal ini, 'Umar bin al-Khatțāb telah berkata: "Dia (Ibn Mas' üd) adalah seorang yang alim dan lembut, seorang qadi dan hakim dan dia seperti sesuatu yang penuh dengan ilmu dan fikah" (Ibn Abi Shaybah, 2006).

Khalifah "Umar bin al-Khațāāb telah melantik 'Ammār sebagai pemerintah di Kufah dan Ibn Mas ūd sebagai wazir dan guru di sana. Perutusan yang ditulis oleh 'Umar adalah sebagaimana berikut "Sesungguhnya aku telah hantarkan kepada kamu semua 'Ammār sebagai pemerintah di Kufah dan 
'Abd Allāh Ibn Mas' ūd sebagai wazir dan guru, kedua-duanya adalah yang terbaik (paling bijak) dalam kalangan sahabat Nabi SAW dan merupakan ahli Badar, dengarlah (taatlah) kepada mereka berdua dan turutlah mereka. Aku telah tinggalkan kamu semua pada Abd Allāh Ibn Mas ūd sebagai wakil diriku”. (Ibn Ḥanbal al-Shaybāni, 1983).

Tersebut dalam sebuah riwayat daripada Ahmad dalam Musnadnya (3422), daripada Abū Zibyān katanya, telah berkata kepadaku "Abd Allāh Ibn 'Abbās: "Jenis qiraat mana yang kamu bacakan?" Maka aku pun berkata, "Bacaan yang pertama. Maka aku pun berkata, "Adakah bacaan Ibn Ummi 'Abd?" Maka ia pun berkata, "Sudah tentu". Dia adalah bacaan yang terakhir. Sesungguhnya Rasulullah SAW dibentangkan kepadanya al-Qur'an setiap tahun (sekali), namun pada tahun yang terakhir, dibentangkan padanya dua kali, dan ketika itu Abd Allāh Ibn 'Abbas juga hadir. Maka dia (Ibn Mas $\bar{u} d)$ mengetahui mana yang dinasakhkan dan mana yang diganti”.

\section{iv. $\quad$ Kepakaran akademik}

Kepakaran dalam dunia akademik membuatkan Ibn Mas ūd r.a menjadi rujukan dalam kalangan sahabat dan tabiin. Perutusan Ibn Mas'ūd r.a ke Kufah oleh Khalifah 'Umar bin al-Khațāâ membuktikan keupayaan dan kemampuan beliau dalam mengasaskan madrasah (pusat pengajian) di Kufah. Khalifah 'Umar bin al-Khaț̣āb mengutuskan surat kepada penduduk Kufah sebagaimana berikut: Daripada Hārith Ibn Mudrib telah berkata: 'Umar telah menulis kepada kami: Sesungguhnya aku telah utuskan kepada kalian 'Ammār Ibn Yāsir sebagai Amir (Ketua Negara) dan Abd Allāh Ibn Mas üd r.a sebagai guru dan menteri (agama). Mereka berdua merupakan orang yang bijak dalam kalangan sahabat Muhammad SAW, (mereka juga) merupakan ahli Perang Badar, dengarlah kamu semua, aku telah melantik Ibn Mas üd r.a sebagai pemegang amanah Baitul Mal, dengar, belajar dan contohilah daripada mereka berdua. Dan aku telah mewakilkan kepada 'Abd Allāh Ibn Mas 'ūd atas diriku" (al-Ḥākim, 1990).

Ketokohan Ibn Mas'ūd turut terserlah dalam bidang al-Qur'an dan qiraat. Ini berdasarkan penjelasan daripada hadis berikut: "Daripada 'Alī Ibn Abi Țālib telah berkata: telah ditanya: Ceritakan kepada kami tentang para sahabat Rasulullah SAW. (Ali) berkata: Yang mana satu? (mereka) berkata: Khabarkan kepada kami tentang Ibn Mas ūd. Kemudian telah berkata (Ali r.a) "Sesungguhnya dia mengetahui al-Qur'an dan al-Sunnah, sampai tamat dan cukuplah (dengan hanya kamu belajar dengannya)" (al-Ḥākim, 1990).

Ketokohan Ibn Mas'ūd turut terserlah dalam ilmu Fikah. Buktinya ialah sebuah kitab yang telah dihasilkan dalam ilmu Fikah dengan bersandarkan kepada pandangan Ibn Mas ūd r.a, iaitu Mawsü at Fiqh 'Abd Allāh Ibn Mas'ūd r.a yang telah dikarang oleh Dr. Muḥammad Rawwās Qal'ahji (1992). Suatu ketika Abū Mūsā Al-'Ash ariyy pernah ditanya tentang suatu masalah lalu dia menjawab bahawa Ibn Mas'ūd telah berselisih dengannya. Maka berkata Abū Mūsā, "Jangan kamu semua bertanya aku selagi 'dakwat' Ibn Mas 'üd r.a masih ada'.

Ibn Mas' $\bar{u} d$ adalah tokoh dalam ilmu periwayatan hadis. Secara keseluruhan terdapat 64 periwayatan hadis yang disandarkan kepada Ibn Mas ūd dalam Sahih Bukhāri dan Muslim (muttafaqun alayh). Manakala dalam Sahih Bukhāri sahaja terdapat tambahan 20 hadis dan dalam Muslim pula terdapat tambahan hadis sebanyak 35 hadis. Begitu juga terdapat 148 hadis yang berulang dalam babbab yang lain.

\subsection{Kontroversi dan Tuduhan Terhadap Ibn Mas'ūd r.a}

Ibn Mas ūd r.a merupakan individu popular dalam pengajian al-Qur'an. Beliau merupakan rujukan dan sahabat yang diiktiraf oleh Rasulullah SAW sebagai menguasai bacaan yang terbaik. Justeru, para musuh Islam akan cuba mencari dan meneroka apa jua maklumat yang boleh dijadikan asas songsang untuk menyerang dan mengambil kesempatan atas keperibadian ${ }^{c} A b d$ Allāh Ibn Mas ${ }^{c} \bar{u} d$ r.a atau pengajian al-Qur'an itu sendiri. 
Serangan yang dilakukan menggunakan nama Ibn Mas ūd r.a tidak hanya termaktub sejak dahulu bahkan ia masih berterusan sehinggalah ke hari ini. Antara yang menjadi kontroversi dan tuduhan atas nama Ibn Mas' ūd r.a ialah tidak memasukkan bacaan al-Mu awwidhatayn dan al-Fätihah dalam mushaf beliau, pendirian Ibn Mas ūd r.a dalam isu pembukuan al-Qur'an, susunan surah al-Qur'an yang berbeza dengan Rasm 'Uthmāni, dan tidak menyerahkan al-Quran dalam simpanannya untuk dibakar.

\subsection{Dakwaan Pertama: Tidak memasukkan al-Mu'awwidhatayn dan al-Fätihah dalam} mushaf al-Quran beliau

Antara perkara utama yang dijadikan hujah oleh para musuh Islam sama ada dulu dan kini berkenaan dengan keaslian al-Qur'an ialah dakwaan bahawa Ibn Mas'ūd r.a tidak memasukkan alMúawwidhatayn dan al-Fätihah dalam mushafnya. Pernyataan ini diperkuatkan oleh hadis berikut yang telah diriwayatkan oleh al-Țabrāni dalam kitabnya al-Mu'jam al-Kabìr. Daripada 'Abd AlRahmō̄n al-Sulami meriwayatkan daripada Ibn Mas' ūd r.a sesungguhnya dia telah berkata: Jangan kamu campurkan dalam al-Qur'an yang bukan daripadanya! Sesungguhnya kedua-dua

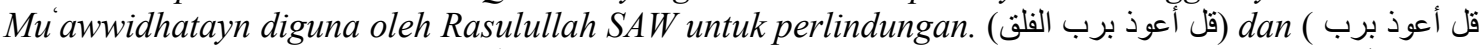
(الناس) telah dibuang oleh Ibn Mas'ūd r.a dalam mushafnya. (al-Ṭabrāni, 1983: 9151 dan Abū 'Ubayd, 1992).

Dakwaan ini juga menegaskan bahawa ia (al-Mu'awwidhatayn) bukan ayat al-Qur'an namun ia merupakan bacaan doa yang dilafazkan oleh Rasululllah SAW sebagai doa pelindung untuk kedua cucunya al-Hasan dan al-Husayn. Hal ini dijelaskan oleh al-Qurțbi (2003) sebagaimana berikut: Ibn Qutaybah telah berkata: Tidak ditulis al-Muawwidhatayn oleh Abd Allāh Ibn Mas' ùd dalam mushafnya kerana beliau mendengar Rasulullah SAW melindungi (cucu baginda) al-Hasan dan alHusayn dengan kedua-dua surah ini.

Antara penulis moden yang masih menggunakan hujah sedemikian ialah Arthur Jeffery yang menyatakan dalam artikelnya bertajuk "The Textual History of the Qur'an". Kenyataan beliau ialah sebagaimana berikut: "Salah satu hakikat sejarah yang tetap akan menimbulkan kemusykilan mengenai sejarah salinan Al-Qur'an adalah perbezaan ketara antara Ibn Mas'üd dan para Sahabat yang lain. Beliau menolak surah 1, surah 113 dan surah 114 serta sanggup mendakwa sesiapa yang menerima surah-surah tersebut ke dalam Kitab Allah sebagai Kafir!! Nabi Muhammad sendiri telah mengesyorkan Ibn Mas'ūd sebagai salah satu daripada empat pembaca Al-Qur'an yang boleh dipercayai."

(Sumber: http://www.answering-islam.org/bahasa/Qur'an/distortion.html)

Jawapan: Dakwaan kononnya Ibn Mas'ūd r.a mengingkari bahawa al-Fätihah dan al$M u^{\mathrm{c} a w w i d h a t a y n}$ adalah dari al-Qur'an sebenarnya ini hanya merupakan satu pendustaan terhadap Ibn Mas ūd r.a. Tidak terdapat satu riwayat yang sahih pun menyatakan sedemikian. Menurut Ibn Hazm sebagaimana yang dinukil oleh al-Nawawi: Ini merupakan pembohongan ke atas Ibn Mas üd r.a, sesungguhnya adalah sahih bahawa qiraat yang diriwayatkan oleh Zār daripada Ibn Mas üd r.a padanya terdapat al-Fātihah dan al-Múawwidhatayn. (al-Nawāwì, 1966).

Selain itu, tidak terdapat satu pun riwayat yang menjelaskan secara langsung kata-kata Ibn Mas ūd r.a dalam pertikaian ini. Kesemua riwayat adalah hanya di peringkat sandaran semata-mata. Ia hanya berdasarkan pengamatan sama ada murid beliau atau perawi terhadap beliau. Berlaku perbezaan atau membuang sesuatu daripada al-Qur'an sedangkan para sahabat lain membacanya adalah sesuatu yang ganjil. Justeru, sekiranya berlaku sedemikian, maka menjadi kewajipan Ibn Mas ūd r.a untuk memastikannya dengan merujuk kepada sahabat yang lain kerana beliau dikenali sebagai seorang yang amanah dengan ilmu. (Aḥmad Ibn Hanbal 1432H).

Selain itu juga ialah penolakan al-Mu awwidhatayn dan al-Fatihah merupakan suatu yang bersifat khabar ahad yang dikira tertolak apabila bertembung dengan khabar mutawätir. Keberadaan naskhah al-Quran rasm 'Uthmānì merupakan hasil daripada riwayat yang mutawātir. Justeru, sekalipun riwayat penolakan itu dinyatakan sebagai sahih ia tetap tertolak kerana bersalahan dengan khabar mutawātir. Berkenaan dengan surah al-Fätihah, ia merupakan suatu yang wajib dihafaz oleh semua Muslimin 
kerana ia adalah rukun dalam solat. Maka bagaimana ia dinafikan oleh Ibn Mas ūd sedangkan ia merupakan suatu yang wajib.

Penyalinan pada zaman 'Uthmān merupakan rentetan daripada pengumpulan yang telah berlaku pada zaman Abū Bakr r.a. Maka sekiranya Ibn Mas ūd tidak bersetuju dengan kemasukan surah alFätihah dan al-Mu'awwizatayn, sudah tentu beliau akan menentang dan menyatakan ketidaksetujuan sejak zaman pengumpulan Abū Bakr r.a lagi. Namun ia tidak berlaku dan Ibn Mas ūd tergolong dalam kalangan mereka yang bersetuju dengan pengumpulan serta kandungannya pada ketika itu.

Pengingkaran terhadap al-Quran sama ada ayat atau surah tentunya akan diambil serius oleh pemerintah. Dalam sejarah dan riwayat juga tidak dinyatakan bahawa terdapat amaran atau hukuman yang dikenakan pemerintah terhadap Ibn Mas'ūd r.a dan muridnya disebabkan menolak sebahagian daripada kandungan al-Quran. Maka dapat disimpulkan di sini bahawa ia merupakan suatu cerita yang palsu dan batil.

\subsection{Dakwaan Kedua: Pendirian Keras Ibn Mas' ūd r.a Dengan Menolak Jawatankuasa Pembukuan al-Qur'an}

Pendirian keras Ibn Mas ūd ini merujuk kepada riwayat bahawa Ibn Shihāb meriwayatkan daripada "Ubayd Allāh Ibn 'Abd Allāh: "A Abd Allāh Ibn Mas'ūd r.a tidak bersetuju (dengan perlantikan Zayd Ibn Thābit) dalam penyalinan al-Quran. Beliau telah berkata: Wahai sekalian muslimin, aku telah disingkirkan daripada tugas penyalinan al-Quran dan tugas itu telah ditangani oleh orang lain (merujuk kepada Zayd). Demi Allah sesungguhnya aku telah masuk Islam, sementara orang itu masih berada dalam kelompok orang kafir. Ia merujuk kepada Zayd Ibn Thābit. (al-Tirmidhi, 1977: 3107)

Satu lagi periwayatan adalah seperti berikut: "Ibn Mas'ūd r.a telah berkata kepada kami: Bagaimana kamu menyuruh membaca qiraat yang telah dibaca oleh Zayd Ibn Thābit setelah aku membaca (ambil) daripada mulut Rasulullah SAW lebih daripada 70 surah, sedangkan Zayd masih kecil berjambul”. (al-Nasa'i : 9330)

Jawapan : Ibn Abī Dāwūd (2002) telah mengumpulkan 15 periwayatan di bawah tajuk 'Keingkaran 'Abd Allāh Ibn Mas' ūd' dalam kitabnya al-Mașāhif. Beliau mengumpulkan semua riwayat yang menunjukkan tentang ketidaksetujuan Ibn Mas ūd terhadap perlantikan Zayd Ibn Thābit, arahan supaya dimusnahkan mashaf, kemarahannya terhadap arahan 'Uthmān, ketegasannya tentang bacaan yang diriwayatkannya serta kesungguhan beliau dalam mencari ketepatan bacaan al-Quran.

Mengenai perkataan Ibn Mas ūd r.a ini perlu dijelaskan bahawa perkataan tersebut tidak menunjukkan al-Quran itu tidak mutawātir dan seterusnya tidak lengkap atau ada tambahan. Apa yang difahami daripada perkataan tersebut ialah Ibn Mas'ūd tidak berpuas hati dengan perlantikan panitia penulisan al-Quran yang diketuai oleh Zayd. Mungkin juga terdapat pandangan bahawa Ibn Mas ūd lebih layak untuk mengetuai jawatankuasa al-Quran berbanding dengan Zayd atau sekurang-kurangnya beliau dilantik untuk bersama dalam jawatankuasa berkenaan. Hakikatnya ini hanya merupakan pandangan beliau sahaja sedangkan pandangan Abū Bakr, "Umar dan 'Uthmān adalah lebih utama berbanding pandangan peribadinya. Oleh kerana itu terdapat juga satu riwayat bahawa pandangan Ibn Mas ūd r.a tersebut tidak begitu disukai oleh para sahabat Nabi yang lain. (al-Tirmidhi 1977, 5:285).

Adalah tidak benar dan satu pendustaan apabila terdapat dakwaan terhadap beberapa orang sahabat yang bertindak membuang sesuatu ayat al-Quran. Inilah yang dikatakan oleh para bahawa Abu Bakr, 'Umar dan 'Uthmān telah menyelewengkan al-Quran dan membuang sesetengah ayat dan surah alQuran. (Mannā' al-Qaț̣̄ān, 1998). Abū Bakr al-Anbāri pula menyatakan : "Pemilihan Zayd Ibn Thabit yang telah dilakukan oleh Abū Bakr, 'Umar dan 'Uthmān berbanding Ibn Mas'ūd, walaupun beliau lebih baik daripada Zayd, lebih awal masuk Islam, lebih utama dan banyak pengalaman. Hanya satu kelebihan Zayd berbanding Ibn Mas 'ùd r.a, iaitu beliau mampu menghafaz keseluruhan ayat al-Qur'an semasa Rasulullah SAW masih hidup berbanding Ibn Mas'üd r.a yang hanya menghafaz al-Quran sebanyak 75 surah sahaja. Dan selebihnya Ibn Mas üd r.a telah menghafaz semasa Rasulullah SAW 
telah wafat. Justeru, orang yang lebih banyak menghafaz al-Quran semasa hayat Rasulullah SAW masih hidup terutamanya untuk mengetuai tugas penyalinan al-Quran.” (al-Qurtubi, 2003)

Abu Bakr al-Anbari kemudiannya menjelaskan: "Pengingkaran atas perlantikan Zayd yang dilakukan oleh Ibn Mas ūd r.a itu adalah timbul berdasarkan kemarahan. Keadaan ini tidak boleh untuk kita menghukum dan sangsi terhadap beliau. Tidak diragukan lagi, iaitu setelah kemarahan itu hilang, Ibn Mas ūd r.a telah mengetahui betapa baiknya pilihan 'Uthmān dan para sahabat Rasulullah SAW bersamanya (dalam penyalinan al-Quran).” (al-Qurțubi, 2003)

Selain itu, penulis berpandangan bahawa pengingkaran terhadap perlantikan Zayd ini berlaku semasa zaman Khalifah 'Uthmān yang menyaksikan berlakunya penyalinan semula al-Quran. Sekiranya Ibn Mas ūd tidak bersetuju dengan perlantikan Zayd maka sudah sepatutnya beliau tidak bersetuju sejak Zayd dilantik pada zaman Abu Bakr yang merupakan zaman pembukuan pertama alQuran. Namun, ia tidak berlaku. Justeru, penulis menganggap ketidaksetujuan Ibn Mas ūd r.a adalah bersifat berita yang sengaja diperbesar-besarkan dan bukanlah kemarahan yang besar.

\subsection{Dakwaan Ketiga: Susunan Surah Yang Berbeza Dengan Mashaf 'Uthmānī}

Apabila merujuk kepada susunan surah yang diriwayatkan dalam Mashaf Ibn Mas'ūd r.a, terdapat perbezaan antara beliau dengan susunan Mashaf 'Uthmāni. Terdapat dua riwayat popular yang menyatakan perbezaan susunan surah menurut Ibn Mas ūd berbanding mashaf 'Uthmāni. Pertama ialah nukilan Ibn Nādim (1997) menyatakan dalam kitabnya al-Fihrist bersumberkan al-Fadl Ibn Syādhan dan kedua ialah nukilan al-Suyūți (1988) dalam kitabnya al-Itqān fi 'Ulūm al-Qur'ān. Sekiranya dibentangkan dalam bentuk jadual, susunan surah yang terdapat dalam periwayatan al-Suyuti dalam alItqān (1988) dan Ibn Nadim (1997) menyatakan dalam kitabnya al-Fihrist adalah seperti berikut:

\section{Perbezaan Susunan Surah Dalam Mashaf Ibn Mas‘ūd}

\begin{tabular}{|c|c|c|c|}
\hline Bil. & $\begin{array}{c}\text { Susunan } \\
\text { berdasarkan } \\
\text { Mashaf 'Uthmāni }\end{array}$ & $\begin{array}{c}\text { Ibn Mas'̄ùd (r.a) } \\
(a l-I t q \bar{a} n)\end{array}$ & $\begin{array}{c}\text { Ibn Mas'īùd (r.a) } \\
\text { (al-Fihrist) }\end{array}$ \\
\hline 1. & Al-Fātihah & Al-Baqarah & Al-Baqarah \\
\hline 2. & Al-Baqarah & Al-Nis $\bar{a}^{\prime}$ & Al-Nis $\bar{a}^{\prime}$ \\
\hline 3. & $\bar{A} l i^{c} \operatorname{Imrān}$ & $\bar{A} l i^{c} \operatorname{Imrān}$ & $\bar{A} l i^{c} \operatorname{Imrān}$ \\
\hline 4. & Al-Nis $\bar{a}^{\prime}$ & $A l-A^{c} r \bar{a} f$ & $A l-A^{c} r \bar{a} f$ \\
\hline 5. & Al-Māidah & $A l-A n^{c} \bar{a} m$ & $A l-A n^{c} \bar{a} m$ \\
\hline 6. & $A l-A n^{c} \bar{a} m$ & Al-Māidah & Al-Māidah \\
\hline 7. & $A l-A^{c} r a \bar{a} f$ & Yūnus & Yūnus \\
\hline 8. & Al-Anfāl & Al-Tawbah & Al-Tawbah \\
\hline 9. & Al-Tawbah & Al-Naḥl & Al-Naḥl \\
\hline 10. & Yӣnus & $H \bar{u} d$ & $H \bar{u} d$ \\
\hline 11. & $H \bar{u} d$ & Yūsuf & Yūsuf \\
\hline 12. & Yūsuf & Al-Kahfi & Al-Isrā' \\
\hline 13. & $A l-R a^{\prime} d$ & Al-Isrā' & Al-Anbiy $\bar{a}^{\prime}$ \\
\hline 14. & Ibrāhim & Al-Anbiya $\bar{a}^{\prime}$ & Al-Mu'minūn \\
\hline 15. & Al-Hijr & Țāhà & $A l-S y u^{c} a r \bar{a}^{\prime}$ \\
\hline 16. & Al-Nahl & Al-Mu'minūn & Al-Șāffāt \\
\hline 17. & Al-Isra $\bar{a}^{\prime}$ & $A l-S y u^{c} a r \bar{a}^{\prime}$ & $A l-A h z a b$ \\
\hline 18. & Al-Kahfi & Al-Ṣāffāt & Al-Qaṣaș \\
\hline 19. & Maryam & Al-Hajj & $A \overline{l-N \bar{u} r}$ \\
\hline 20. & Ṭăhā & Al-Qașaș & Al-Anfāl \\
\hline 21. & Al-Anbiy $\bar{a}^{\prime}$ & Al-Naml & Maryam \\
\hline 22. & Al-Haj & $A l-N \bar{u} r$ & Al- ${ }^{c} A n k a b \bar{u} t$ \\
\hline 23. & Al-Mu'minūn & Al-Anfāl & $A l-R \bar{u} m$ \\
\hline 24. & $A l-N \bar{u} r$ & Maryam & Yāsin \\
\hline 25 . & Al-Furqān & Al- ${ }^{c}$ Ankabūt & Al-Furqān \\
\hline 26. & $A l-S y u^{c} a r \bar{a}^{\prime}$ & Al-Rūm & Al-Haj \\
\hline 27. & Al-Naml & Yāsin & $A l-R a^{c} d$ \\
\hline
\end{tabular}




\begin{tabular}{|c|c|c|c|}
\hline 28. & Al-Qașaș & Al-Furqān & $S a b a^{\prime}$ \\
\hline 29. & Al-' ${ }^{c}$ Ankabūt & Al-Hijr & Fāṭir \\
\hline 30. & $A l-R \bar{u} m$ & $A l-R a^{c} d$ & Ibrāhìm \\
\hline 31. & Luqmān & $S a b a^{\prime}$ & Șād \\
\hline 32. & Al-Sajdah & Fāṭir & Muhammad \\
\hline 33. & $A l-A h z \bar{a} b$ & Ibrāhīm & Al-Qamar \\
\hline 34. & $S a b \bar{a}^{\prime}$ & Șād & Al-Zumar \\
\hline 35. & Fātir & Muḥammad & Ghāfir \\
\hline 36. & Yāsin & Luqmān & Al-Zukhruf \\
\hline 37. & Al-Ṣāffāt & Al-Zumar & Fușṣilat \\
\hline 38. & Șād & Ghāfir & Al-Ahqaf \\
\hline 39. & Al-Zumar & Al-Zukhruf & Al-Jāthiyah \\
\hline 40. & Ghāfir & Fușșilat & Al-Dukhān \\
\hline 41. & Fușșilat & Al-Shūrā & Al-Fath \\
\hline 42. & Al-Syūra & Al-Ahqaf & Al-Hadid \\
\hline 43. & Al-Zukhruf & Al-Jāthiyah & Al-Hasyr \\
\hline 44. & Al-Dukhān & Al-Dukhān & Al-Sajdah \\
\hline 45. & Al-Jāthiyah & Al-Fath & $Q \bar{a} f$ \\
\hline 46. & Al-Ahqaf & Al-Hasyr & Al-Ṭalāq \\
\hline 47. & Muhammad & Al-Sajdah & Al-Hujurāt \\
\hline 48. & Al-Fath & Al-Talāq & Al-Mulk \\
\hline 49. & Al-Hujurāt & Al-Qalam & Al-Taghābun \\
\hline 50. & $Q \bar{a} f$ & Al-Hujurāt & Al-Munāfiqūn \\
\hline 51. & Al-Z̄āriyāt & Al-Mulk & Al-Jumu'ah \\
\hline 52. & Al-Ṭūr & Al-Taghābun & Al-Șāf \\
\hline 53. & Al-Najm & Al-Munāfiqūn & Al-Jin \\
\hline 54. & Al-Qamar & Al-Jumu'ah & $N \bar{u} h$ \\
\hline 55. & Al-Rahman & $A l-S \bar{a} f$ & Al-Mujādalah \\
\hline 56. & $A l-W \bar{a} q i^{c} a h$ & Al-Jin & Al-Mumtahana \\
\hline 57. & Al-Hadid & $N \bar{u} h \underline{h}$ & Al-Tahrīim \\
\hline 58. & Al-Mujādalah & Al-Mujādalah & Al-Raḥmān \\
\hline 59. & Al-Hasyr & Al-Mumtahanah & Al-Najm \\
\hline 60. & Al-Mumtahanah & Al-Tahrīim & Al-Zāriyāt \\
\hline 61. & $A l-S \grave{a} f$ & Al-Raḥmān & $A l-T \bar{u} r$ \\
\hline 62. & Al-Jumu'ah & Al-Najm & Al-Qamar \\
\hline 63. & Al-Munāfiqūn & $A l-T \underline{u} r$ & Al-Ḧāqqah \\
\hline 64. & Al-Taghābun & Al-Zāriyāt & $A l-W \bar{a} q i^{c} a h$ \\
\hline 65. & Al-Ṭalāq & Al-Qamar & Al-Qalam \\
\hline 66. & Al-Ṭahrim & $A l-W \bar{a} q i^{c} a h$ & $A l-N \bar{a} z i^{\prime} \bar{a} t$ \\
\hline 67. & Al-Mulk & $A l-N \bar{a} z i^{\prime} \bar{a} t$ & Al-Ma'ārij \\
\hline 68. & Al-Qalam & Al-Ma'ārij & Al-Muddaththi \\
\hline 69. & Al-Hāqqah & Al-Muddaththir & Al-Muzzammil \\
\hline 70. & $A l-M a^{c} \bar{a} r i j$ & Al-Muzzammil & Al-Muțaffifin \\
\hline 71. & $N \bar{u} h$ & Al-Muṭaffifin & ${ }^{c}$ Abasa \\
\hline 72. & Al-Jin & 'Abasa & Al-Insān \\
\hline 73. & Al-Muzzammil & Al-Insān & Al-Qiyāmah \\
\hline 74. & Al-Muddaththir & Al-Mursalāt & Al-Mursalāt \\
\hline 75. & Al-Qiyāmah & Al-Qiyāmah & $A l-N a b a^{\prime}$ \\
\hline 76. & Al-Insān & $A l-N a b a^{\prime}$ & Al-Takwīr \\
\hline 77. & Al-Mursalāt & Al-Takwīr & Al-Infițār \\
\hline 78. & $A l-N a b a^{\prime}$ & Al-Infițār & Al-Ghāshiyah \\
\hline 79. & $A l-N \bar{a} z i^{c} \bar{a} t$ & Al-Ghäshiyah & $A l-A^{c} l a$ \\
\hline 80. & ${ }^{c}$ Abasa & $A l-A^{c} l \bar{a}$ & Al-Layl \\
\hline 81. & Al-Takwīr & Al-Layl & Al-Fajr \\
\hline 82. & Al-Infițār & Al-Fajr & Al-Burūj \\
\hline 83. & Al-Mutaffifiin & Al-Burūj & Al-Insyiqāq \\
\hline 84. & Al-Insyiqāq & Al-Insyiqāq & Al-c Alaq \\
\hline 85. & Al-Buruj & Al- ${ }^{c}$ Alaq & Al-Balad \\
\hline 86. & Al-Ṭāriq & Al-Balad & Al-Ḍuḥ̄a \\
\hline 87. & $A l-A^{c} l \bar{a}$ & Al-Ḍuhā & Al-Sharh \\
\hline
\end{tabular}




\begin{tabular}{|c|c|c|c|}
\hline 88. & Al-Ghāsyiyah & Al-Tāriq & Al-Tāriq \\
\hline 89. & Al-Fajr & Al-' ${ }^{c}$ disyāt & Al-' Adiyāt \\
\hline 90. & Al-Balad & $A l-M a^{c} \bar{u} n$ & $A l-M a^{c} \bar{u} n$ \\
\hline 91. & Al-Shams & Al-Qāri'ah & Al-Qāri'ah \\
\hline 92. & Al-Layl & Al-Bayyinah & Al-Bayyinah \\
\hline 93. & Al-Duhạa & Al-Shams & Al-Shams \\
\hline 94. & Al-Sharh & Al-Tīn & Al-Tīn \\
\hline 95. & Al-Tìn & Al-Humazah & Al-Humazah \\
\hline 96. & Al- ${ }^{-}$Alaq & Al-Fīl & Al-Fīl \\
\hline 97. & $A l-Q a d r$ & Quraysh & Quraysh \\
\hline 98. & Al-Bayyinah & Al-Takāthur & Al-Takāthur \\
\hline 99. & Al-Zalzalah & $A l-Q a d r$ & $A l-Q a d r$ \\
\hline 100. & Al-c $\bar{A} d i y \bar{a} t$ & Al-Zalzalah & $A l^{c} A s \underline{r} r$ \\
\hline 101. & $A l-Q \bar{a} r i^{c} a h$ & $A l-^{c} A s ̦ r$ & Al-Nașr \\
\hline 102. & Al-Takāthur & Al-Nașr & Al-Kawthar \\
\hline 103. & $A l-^{c} A s \underline{r}$ & Al-Kawthar & Al-Käfirūn \\
\hline 104. & Al-Humazah & Al-Kāfirūn & Al-Masad \\
\hline 105. & Al-Fīl & Al-Masad & Al-Ikhlāṣ \\
\hline 106. & Quraysh & Al-Ikhlāṣ & \\
\hline 107. & $\overline{A l-M \bar{a}^{c} \bar{u} n}$ & Al-Sharh & \\
\hline 108. & Al-Kawthar & & \\
\hline 109. & Al-Kāfirūn & & \\
\hline 110. & Al-Nașr & & \\
\hline 111. & Al-Masad & & \\
\hline 112. & Al-Ikhlās & & \\
\hline 113. & Al-Falaq & & \\
\hline 114. & $A l-N \bar{a} s$ & & \\
\hline
\end{tabular}

Secara keseluruhan, terdapat perbezaan yang amat ketara antara periwayatan mengikut susunan surah yang disandarkan kepada Ibn Mas' ūd berbanding Mashaf 'Uthmāní. Sekiranya diteliti satu persatu maka kita akan dapati sebanyak 7 surah tidak disenaraikan dalam periwayatan bersumberkan Ibn Mas ūd yang dinyatakan dalam al-Itqān karangan al-Suyūți (1988), iaitu surah al-Fātihah, Qāf, alHadìd, al-Hāqqah, al-Falaq dan al-Nās. Manakala terdapat 10 surah yang tidak disenaraikan dalam periwayatan bersumberkan Ibn Mas' ${ }^{\mathrm{u}} \mathrm{d}$ yang dinyatakan dalam al-Fihrist karangan Ibn Nādim iaitu alFātihah, al-Hijr, al-Kahfi, Tāhā, al-Naml, Luqmān, al-Syūra, al-Zalzalah, al-Falaq dan al-Nās. Penulis mengandaikan terdapat pengguguran surah dalam kedua-dua periwayatan ini yang berpunca daripada kesilapan periwayatan dan kelemahan perawi. Hal ini demikian kerana banyak perbincangan tentang perbezaan antara mashaf 'Uthmāni dan Ibn Mas'ūd berlaku hanya sekitar tiga surah sahaja, iaitu alFatihah, al-Falaq dan al-Nās.

Al-Nādim (1978) telah memberikan komentar berkenaan periwayatan ini dengan menyatakan bahawa beliau pernah melihat pelbagai mashaf yang dikaitkan dengan Ibn Mas ūd, akan tetapi beliau tidak pernah melihat dua naskah yang mempunyai persamaan antara satu sama lain. Selain itu, beliau juga menemui satu naskah mashaf yang dikaitkan dengan Ibn Mas'ūd pada abad kedua Hijrah yang terdapat surah al-Fätihah. Namun al-Nādim (1978) menyatakan beliau mengutamakan pandangan daripada al-Fadl bin Shādhan kerana beliau merupakan pakar dalam bidang al-Quran dan Qiraat berbanding dirinya. Kenyataan ini juga disokong berdasarkan kenyataan Muhammad Ibn Isḥāq (2004) berkata: "Saya telah melihat banyak Mașāhif penulis yang mereka sifatkan Ibnu Mas $\bar{u}^{\mathrm{u}}$ tetapi tidak ada dua Masahif bersetuju dengan satu sama lain ... saya telah melihat mashaf yang ditulis kira-kira 200 tahun yang lalu di mana surah al-Fātihah telah ditulis."

Berdasarkan analisis yang dibuat, tiada seorang pun murid Ibn Mas ūd r.a yang meriwayatkan bahawa terdapat perbezaan dalam susunan mashaf Ibn Mas ūd. Pertama kali ia didapati ialah dalam abad ke 3 H melalui sanad al-Fadl Ibn Shādhān $(260$ H) dan Abū Ja far Muhammad Ibn 'Abd al-Hamíd $(188 \mathrm{H})$. Seandainya Mashaf Ibn Mas'ūd wujud sedemikian, maka ia boleh disimpulkan sebagai ada kemungkinan mashaf-mashaf tersebut telah dicatat sebelum semakan terakhir antara Rasulullah SAW dengan Jibril a.s. Selain itu, jelas datangnya daripada banyak hadis sahih yang menjelaskan bahawa susunan banyak surah al-Quran sememang berlakunya semasa hayat Rasulullah. Selain itu, Abu Hayyan al-Naḥāwi (1993) menyatakan bahawa berdasarkan penelitian kepada pelbagai sumber bacaan jelaslah 
bahawa kebanyakan riwayat yang dikaitkan dengan Ibn Mas ūd adalah datang daripada sumber kelompok Syiah. Sementara para ilmuwan Sunni di sisi lain menyatakan bahawa bacaan Ibn Mas ùd adalah selari dengan bacaan seluruh umat Islam.

\subsection{Tidak Menyerahkan Mashaf untuk Dibakar}

Dakwaan ini dikemukakan berasaskan kepada periwayatan berikut: Setelah itu dia (Ibn Mas ūd) berkata lagi: Wahai semua penduduk Iraq, sembunyikan mashaf yang kalian miliki dan jangan menampakkan ia. Ini kerana Allah telah berfirman (Siapa yang mengkhianati (dalam urusan rampasan perang), maka Allah akan mendatangkan apa yang dia khianati itu pada hari kiamat). (al-Tirmidhi, 1977 :3107)

Rentetan daripada perselisihan dan kemarahan Ibn Mas'ūd r.a terhadap perlantikan Zayd bin Thābit menyebabkan beliau mengarahkan semua muridnya agar menyembunyikan mashaf yang ada pada mereka. Ini bermaksud beliau menentang keputusan Khalifah 'Uthmān yang memerintahkan agar diserahkan mashaf beliau untuk dilupuskan dan menerima Maṣhaf 'Uthmāni sebagai al-Quran yang sah.

Al-Ṭabari (2000) menyatakan bahawa orang pertama yang menghapuskan mashaf yang menyalahi Maṣhaf al-Imām ini ialah 'Uthmān sendiri. Ini berdasarkan ungkapan 'Uthmān iaitu: "Sesungguhnya aku telah membuat (keputusan) itu dan ini, aku telah hapuskan apa yang ada pada aku, maka kamu semua hapuskan apa yang ada pada kalian semua".

Al-Zarqāni (1995) menyatakan bahawa perbuatan menghapuskan tulisan al-Quran ini merupakan suatu tugas yang berat dalam kalangan sahabat kerana sifat sayang dan cinta mereka kepada mashaf akan menjadikan mereka berat hati untuk menghapuskannya. Namun kepentingan dan kemaslahatan ummah lebih utama mengatasi kepentingan peribadi. Ibn Hajar $(1380 \mathrm{H})$ menyatakan bahawa tidak ada seorang pun sahabat yang mengingkari suruhan untuk menghapuskan mashaf masing-masing dan hanya merujuk kepada mashaf al-Imām. Justeru, ini menunjukkan ketaatan semua sahabat adalah termasuk ${ }^{c}$ Abd Allāh Ibn Mas ${ }^{c} \bar{d}$ r.a.

Al-Zarqani (1995) juga menyatakan semua orang bersetuju dengan Mashaf 'Uthmāni termasuklah Ibn Mas ūd yang telah bersetuju dan seterusnya membakar mashaf yang ada pada beliau. Tindakan Ibn Mas ūd ini telah menunjukkan beliau bersama-sama dengan keputusan sahabat dan kaum Muslimin. Setelah itu, masalah berkenaan dengan bacaan yang pelbagai serta pertelingkahan yang berlaku dalam kalangan umat Islam dapat diatasi dan menjadikan umat Islam bertambah kuat dan erat.

Dalam situasi ini, penulis mengandaikan kerja pembakaran dan penghapusan mashaf hanya tertakluk kepada bacaan yang bersalahan dengan mashaf 'Uthmāni, bukan melibatkan keseluruhan mashaf. Para sahabat telah bertindak memurnikan tulisan al-Quran yang ada pada mereka mengikut mashaf al-Imam.

\subsection{Kesimpulan}

Ibn Mas'ūd r.a merupakan tokoh sahabat yang ulung dalam kalangan para sahabat Rasulullah SAW. Ketokohan beliau dibuktikan berdasarkan kenyataan daripada al-Quran, Hadis Rasulullah SAW, athar daripada para sahabat dan tabiin. Beliau juga merupakan pakar rujuk utama dalam pengajian alQuran, Fikah dan Hadis. Maka berasaskan ketokohan beliau ini membuatkan para musuh Islam selalu menjadikan beliau sebagai sasaran.

Dalam pengajian al-Quran, para musuh Islam selalu menggunakan hujah yang kononnya dipetik daripada Ibn Mas ūd r.a. Tujuan para musuh Islam ialah ingin mengkritik aspek ketulenan dan keaslian al-Quran. Mereka juga menyentuh tentang bacaan al-Quran (qiraat) yang dinisbahkan kepada Ibn Mas ūd r.a adalah bercanggah dengan Mashaf 'Uthmāni. Berdasarkan kajian dan penelitian, anak murid Ibn Mas ūd r.a sendiri tidak ada yang meriwayatkan qiraat berkenaan seperti Masrūq bin al-Ajdā' 
Hamadāni, Aswad bin Yazìd dan 'Alqamah bin Qays Nakha i. Justeru, ia merupakan suatu pendustaan dan banyak berlaku periwayatan yang lemah (da if) dan direka (mawdī ).

Kesimpulannya, walaupun pelbagai isu kontroversi telah dipalitkan kepada Ibn Mas' ūd r.a namun hakikatnya ia tidak mengurangkan ketokohan serta kredibiliti beliau dalam sejarah Islam. Segala tohmahan dan kontroversi mengenai Ibn Mas' ūd telah berjaya dijawab dengan baik oleh para ilmuwan dan sarjana Islam yang sekaligus memeliharanya daripada keraguan dan kritikan terhadap ketulenan alQuran. Untuk kajian lain pada masa depan adalah sesuai sekiranya dinilai dakwaan yang menyentuh tentang bacaan al-Quran yang dikatakan bercanggah dengan Mashaf 'Uthmāni. Ia boleh dinilai sama ada dalam konteks tulisan, bacaan serta kesahihan riwayat agar keraguan terhadap ketulenan mashaf dapat dirungkaikan secara lebih akademik dan terperinci.

\section{Rujukan}

. (1983). Fadā'il al-Ṣahabah. Beirut : Muassasat al-Risālah.

'Abd Allāh Al-Māmaqānì. (1424H). Tanqīh Al Maqāl Fi Aḥwāl Al-Rijāl . Qum, Iran : Āli Bayt Li Ihyā' al-Turāth.

Abū 'Ubayd al-Qāsim. (1992). Fadā'il al-Qur'ān wa Ma'ālimuhu wa Ādābuhu. Arab Saudi : Wizārah al-Awqāf wa al-Shu'ūn al-Islāmiyyah.

Aḥmad '̄̄sā al-Ma șarawi. (2006). al-Qirā' āt al-Wāridah fi al-Sunnah. Kaherah : Dār al-Salām.

Al-Bukhāri, Muḥammad bin Ismā īl bin Ibrāhim bin al-Mughīrah. (1993). Șaḥịh al-Bukhāri : al-Musnad min Hadith Rasūl Allah SAW min Sunanih wa Ayyāmih. Damsyik: Dār al-Ulūm al-Insāniah.

Al-Dhahabi, Muḥammad bin Aḥmad bin 'Uthmān Shams al-Dīn. (2001). Siyār A'lām al-Nubalā'. Qāhirah : Mu'assasat al-Risālah.

Al-Ḥākim, Muḥammad bin 'Abd Allāh bin Abū 'Abd Allāh al-Ḥākim al-Naysabūri. (1990). alMustadrak Alā al-Șahihhayn. Beirut : Dār al-Kutub al-Ilmiyyah.

‘Alī bin Ibrāhim Qummì. (1404H). Tafsìr al-Qummì. Qum, Iran : Muassasah Dār al-Kitāb Li al-Ṭibā' ah wa al-Nashr.

al-Khaw'ì, al-Sayyid Abū al-Qāsim. (1398H). Mujam al-Rijāl . Tehran : Muassasah al-Khaw’ì alIslāmiyyah.

Al-Nasā’'i, Abū 'Abd al-Raḥmān Aḥmad bin Shu'ayb. (1999). Sunan al-Nasā'i. Beirut : Maktabat alMa'ārif.

Al-Nawāwì, Abū Zakariyyā Muhy al-Dīn Yahya bin Sharaf. (1966). Al-Majmī Sharh al-Muhazzab. Bierūt : Dār al-Fikr.

Al-Qurțubi, Abū 'Abd Allāh Muḥammad bin Aḥmad bin Abì Bakr al-Anșúriyy al-Khazrajiyy. (2003). Al-Jāmi li Aḥkām al-Qur'ān. Riyadh : Dār 'Alam al-Kutub.

Al-Sakhāwi, 'Ilm al-Dīn. (2008). Jamāl al-Qurrā' wa Kamāl al-Iqrā'. Makkah: Maktabah al-Turāth.

Al-Suyūṭi, Jalāl al-Dīn Abd al-Raḥman bin Abī Bakr. (1988). Al-Itqān fi 'Ulūm al-Qur'ān. Tahqiq: Muḥammad Abū al-Fạ̣l Ibrāhim. Beirut: Maktabah al-'Așriyyah.

Al-Ṭabarī, Muhammad bin Jarì bin Yazīd bin Kathïr Abū Ja'far. (2000). Jāmi ‘ al-Bayān fi Ta ’wì alQur'ān. Beirut: Mu'assasat al-Risālah.

Al-Ṭabrāni, Sulaymān bin Aḥmad. (1983). Al-Mu jam al-Kabīr. Maktabat al-'Ulūm wa'l-Hukm.

Al-Tirmidhī, Muḥammad bin 'Īsā bin Sawrah bin Mūsa al-Ḍaḥ̣āk. (1977). Sunan al-Tirmidhì. Mușțafā al-Bābi al-Ḥalabì.

Al-Zarqānī, Muhammad Abd al-Aẓīm. (1995). Manāhil al-Irfān fi 'Ulūm al-Qur'ān. Beirut : Dār alKutub al-'Arabi. 
Ahmad Zulfiqar Shah bin Abdul Hadi \& Abdul Nasir bin Abd Latif / UMRAN - International Journal of Islamic and

Civilizational Studies. vol.1 no.1 (2014) $22-34$

Arthur Jeffery. (2014) "The Textual History of the Qur'an". http://www.answeringislam.org/Books/Jeffery/thq.htm . Tarikh akses : 26 Ogos 2014.

Ibn 'Abd al-Barr, Yūsuf 'Abd Allāh Muhammad. (1412H). al-Istì āb fi Ma rifat al-Asḥ̂āb. Beirut : Dār al-Jīl.

Ibn Abī Dāwūd, Abū Bakr 'Abd Allāh bin Sulaymān al-As atn al-Sajistāni. (2002). Kitāb al-Maṣāhịf. Beirut : Dār al-Bashā'ir al-Islāmiyyah.

Ibn Abì Hātim, 'Abd al-Rahmmān bin Muhammad bin Idrīs al-Tamīmì. (1419H). Tafsìr al-Qur'ān alAżìm Li Ibn Abì Hạtim. Saudi : Maktabah Nizāar Musțafa al-Bāz.

Ibn Abī Shaybah, Abū Bakr 'Abd Allāh bin Muḥammad. (2006). Muṣannaf Ibn Abī Shaybah. Dār alQiblah, Muassasah 'Ulūm al-Qur'ān.

Ibn al-Athīr al-Jazarì. (1987). Al-Kāmil fi al-Tārikh. Beirut : Dār al-Kutub al-'Ilmiyyah.

Ibn al-Qayșarāni, Muhammad bin Țāhir bin 'Alī. (1994). Tazkirah al-Huffāz (Atrāaf al-Ahāadith alMajrūḥin Li Ibn Hibbān. Riyadh : Dār al-Ṣamī' Li al-Nashr wa al-Tawzī’

Ibn Ḥajar, Aḥmad Ibn Ali Ibn Ḥajar al-'Asqalānì. (2008). Fath al-Bāri bi Sharh Ṣaḥịh al-Bukhāri. Beirut : Dār al-Ma'rifah.

Ibn Ḥanbal, Abū Abd Allāh Aḥmad bin Muḥammad bin Ḥanbal-Shaybāni. (1993). Musnad al-Imām Ahmmad. Beirut : Dār Ihyā' al-Turāth al-'Arabī.

Ibn Ḥibbān, Muḥammad bin Ḥibbān bin Aḥmad bin Ḥibbān bin Mu'ādh bin Ma bad. (1417H). al-Sïrah al-Nabawiyyah wa Akhbār al-Khulafā'. Beirut : al-Kutub al-Thaqāfiyyah.

Ibn Isḥāq, Muḥammad Ibn Yasār Ibn Khiyār. (2004). Al-Sīrah al-Nabawiyyah. Beirut : Dār al-Kutub al-Ilmiyyah.

Ibn Nadīm, Abū al-Farj Muhammad bin Isḥāq bin Muhammad al-Warrāq. (1997). al-Fihrist. Beirut : Dār al-Ma rifah.

Maḥmūd Shalabì . (1995). Hayāt 'Abd Allāh bin Mas' 'ùd. Beirut : Dār al-Jìl.

Mannā‘ Khalīil al-Qațāān. (1998). Mabāhith fi 'Ulūm al-Qur'ān. Beirut : Mu'assasah al-Risālah.

Muhammad Rawwās Qal'ah Jì. (1984). Mawsū ah 'Abd Allāh bin Mas' ūd. Beirut : Dar al-Nafā'is.

Muslim bin al-Ḥajjāj Abū al-Ḥasan al-Qushayrī. (1365H). al-Jāmi al-Ṣaḥihh al-Musammā Șaḥịh Muslim. Beirut : Dār Ihyā’ al-Turāth al-'Arabī. 